\title{
Comparative analysis of low-energy buildings to help achieve carbon neutrality technology
}

\author{
Zhang Zhizheng ${ }^{1}$, Hou Qingying ${ }^{1}$, Tao Jin $^{2}$, Zhang Hao ${ }^{1}$, Chou Xuesong ${ }^{3}$, Jiang Xiangting ${ }^{1}$ \\ ${ }^{1}$ School of Energy and Power, ChangChun Institute of Technology, Changchun Jilin. \\ ${ }^{2}$ School of Municipal and Environmental Engineering, Jilin University of Architecture Technology, Changchun Jilin. \\ ${ }^{3}$ School of Municipal and Environmental Engineering, Jilin Jianzhu University, Changchun Jilin.
}

\begin{abstract}
The development of low-energy buildings is an important initiative to achieve carbon peaking by 2030 and carbon neutrality by 2060 . According to the data of the relevant papers, if all the northern urban and rural buildings in China adopt passive ultra low energy building technology, it can save about 350 million tons of coal for heating and reduce about 900 million tons of carbon dioxide emissions each year. It's of great significance to achieve the goals of "peak carbon dioxide emissions" and "carbon neutrality". Starting from four key technologies for low-energy buildings, explanation and analysis the energy-saving methods for low-energy buildings, It also presents the challenges and suggestions for the development of low-energy buildings in China.
\end{abstract}

\section{Preface}

In recent years, the issue of energy has gradually attracted widespread discussion and attention in the international community, in order to actively address the problems of global warming, environmental pollution and clean energy consumption, etc. On September 22, 2020, at the 75th General Debate of the United Nations General Assembly, General Secretary Xi solemnly announced that "China will increase its independent national contribution, adopt more vigorous policies and measures, strive to peak CO2 emissions by 2030, and strive to achieve carbon neutrality by 2060."[1] According to the International Energy Agency, energy consumption in buildings accounts for about $32 \%$ of the world's energy consumption ${ }^{[2]}$.

Actively promote the transformation and upgrading of traditional buildings to new buildings, and develop low-energy buildings without delay.

On March 13, 2021, the "Outline of the Fourteenth Five-Year Plan of the National Economic and Social Development of the People's Republic of China and the Vision 2035" was released to the public, and the vigorous development of low-carbon and low-energy buildings was included in it ${ }^{[3]}$.

With the continuous promotion of policies related to building science, low-energy buildings have achieved rapid development ${ }^{[4]}$. This paper mainly analyzes the energy efficiency of four key technologies of low-energy buildings, clarifies the advantages of low-energy buildings in terms of external envelope structure, fresh air system and renewable energy utilization, and puts forward some problems and suggestions of low-energy buildings in the process of their development, provides a basis for future research and development of low-energy buildings, and further provides theoretical references for the realization of national carbon neutral strategy.

\section{Low-energy buildings}

Low-energy buildings aim to achieve a healthier and more comfortable indoor environment and improve people's comfort by adopting integrated envelope technology, high-efficiency fresh air system, renewable energy heating technology and solar photovoltaic technology to save energy and reduce emissions according to the different climatic characteristics and natural resource environment conditions of each region.

\section{Key technologies for low-energy buildings}

\subsection{Envelope integration technology}

\subsection{1, Extra thick outer insulation layer}

The size of the insulation layer of indoor and outdoor walls of ordinary insulated buildings is about $80 \mathrm{~m}$ thick, and the thickness of the insulation layer of low-energy buildings is usually larger than $100 \mathrm{~mm}{ }^{[5]}$, which is equivalent to putting a "down jacket" on the outer layer of low-energy buildings to reduce the cold wind and heat diffusion to the outside. 


\subsection{2, Insulation of walls}

The common building only insulates the exterior walls, while the low energy building interval walls and floor slabs need to be set up with insulation, which is equivalent to putting "warm underwear" on each room, effectively preventing heat transfer between households and avoiding large fluctuations in indoor temperature due to adjacent users "rubbing warmth".

\subsection{3, Energy-saving exterior doors and windows}

Low-energy buildings have high insulation effect and energy-saving closed doors and windows, the heat insulation capacity is 2-3 times that of traditional doors and windows, and the excellent heat insulation performance makes the temperature difference between the surface of exterior doors and windows and the interior stay within $3^{\circ} \mathrm{C}$, which reduces the cold and heat radiation effect of exterior doors and windows and plays an important role in improving the indoor thermal comfort environment.

\subsection{4, High airtightness}

The doors and windows of the exterior walls of low-energy buildings have good indoor air convection effect and airtightness; in addition, both sides of the door and window frames and the top of the partition walls are equipped with a layer of waterproof, wind-resistant and steam-resistant film. It is similar to adding a waterproof and windproof "punching jacket" inside the whole room. When the pressure difference between indoor and outdoor is 50pa, due to the leakage and infiltration of air conditioning doors and windows, the number of air changes in ordinary heating buildings is much greater than the number of air changes in low-energy buildings, and the good airtightness of low-energy buildings can effectively prevent the hot and cold outdoor air from penetrating into the room through the gaps, causing a significant change in the relative indoor temperature and relative indoor humidity, and the high airtightness reduces the building energy consumption and increases the comfort of the building. It is conducive to the realization of the general policy of national energy conservation and emission reduction ${ }^{[6]}$.

\subsection{Renewable energy heating technology}

Geothermal energy and solar energy are considered as a kind of renewable environmental energy hidden in nature, and they have a very high utilization value ${ }^{[7]}$, and the adoption of renewable energy heating for low-energy buildings will have an important impact on the protection of the environment and the reduction of carbon emissions.

\subsection{1, Geothermal energy heating technology}

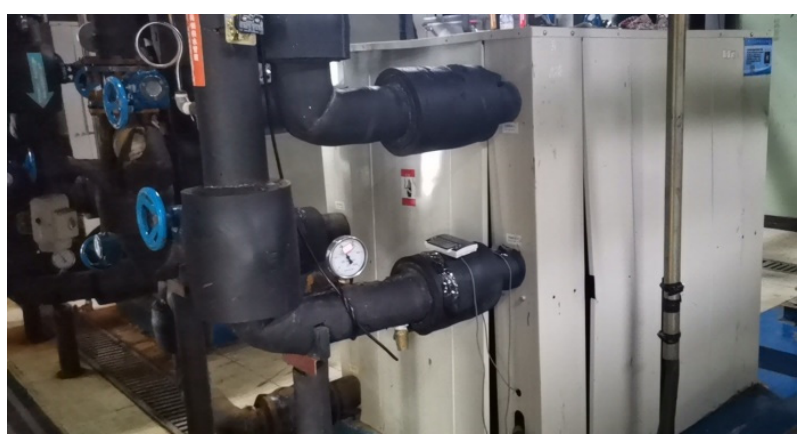

Fig.1 Ground source heat pump

Geothermal energy heating is a kind of heating method with high economic efficiency and friendly to the environment. At present, China has considerable geothermal energy resources due to its vast territory, and the application of abundant geothermal energy resources to building heating will undoubtedly have a positive effect on protecting the environment and saving water resources.

With the maturity of clean energy and engineering technology in recent years, geothermal energy has been widely used. Geothermal energy can replace coal, nuclear energy and natural gas energy, and is widely used not only for power generation, but also for direct heating, and its reserves are about the energy needed to burn 500 billion tons of standard coal.

\subsection{2, Solar Heating Technology}

Solar energy is the key to meet the growing demand for energy. The use of solar energy is not restricted by geography, and the energy is abundant, clean and safe without pollution. Solar heating systems consist of solar collectors, energy storage tanks, and heat dissipation components, etc. Solar collectors collect solar radiation to produce heat energy, which is then transferred to the heat transfer mass, and finally the heat is delivered to the heating end devices through water. Maximizing the efficiency of solar energy use can save at least $40 \%$ of energy costs and greatly reduce operating costs ${ }^{[8]}$. The full and effective use of solar heating in low-energy buildings is bound to produce good energy savings in the coming years.

\subsection{Fresh air heat recovery technology}

The fresh air system is an independent air treatment system consisting of a fresh air ventilation system and its related accessories. The fresh air ventilator filters and purifies the fresh air from outdoors, and then delivers it directly to the room through the pipeline. Users in the indoor space, under the conditions of closed doors and windows, to ensure that the air inside the house clean, so that people as in the fresh nature. Under the condition of closed windows, the fresh air system circulates indoor and outdoor air flow 24 hours a day, discharging the dirty indoor air from the ducts and continuously introducing fresh indoor air after purification and filtering, ensuring 
fresher indoor air. In addition, although the new air system is automatically turned on within 24 hours, its power consumption is not much different from that of a household refrigerator because of its relatively low operating efficiency ${ }^{[9]}$.

The fresh air system with full heat exchange function means that when the indoor air conditioning return air and fresh air flow through the heat exchange core in a positive cross way, there is a temperature difference and water vapor pressure difference between the airflow on both sides of the flat partition, and the heat and mass transfer between the two airflows at the same time, resulting in full heat exchange ${ }^{[10]}$. It can not only easily realize heat recovery and improve indoor heat exchange efficiency with large central air conditioning for cooling and heating, but also effectively avoid the rapid loss of indoor energy, which is more environmentally friendly and energy-saving.

\subsection{Solar photovoltaic technology}

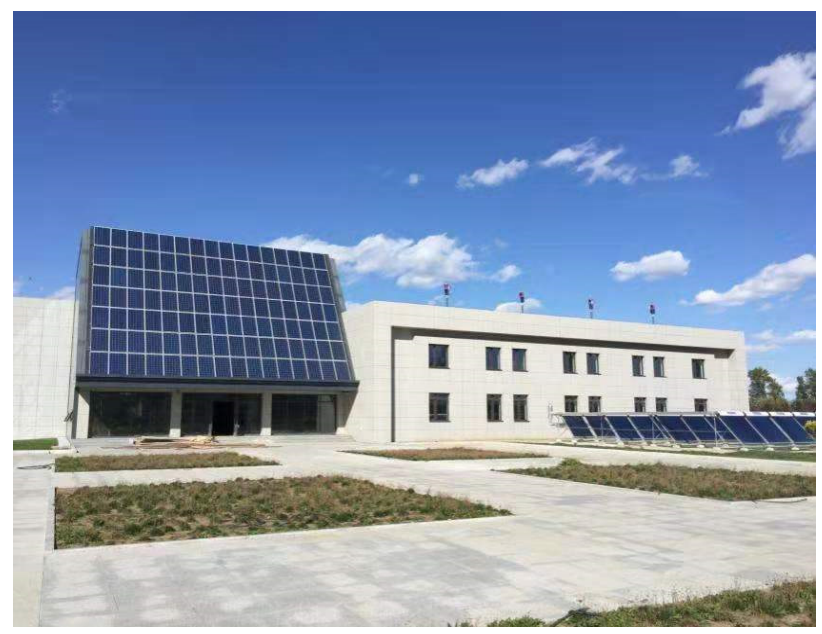

Fig.2 Solar photovoltaic building integration

The combination of solar photovoltaic technology and building, in the low energy consumption building periphery and the main structure of the surface respectively through the deployment of photovoltaic devices to directly generate photovoltaic energy, can promote the low energy consumption building to produce more high-quality green clean energy, solar photovoltaic technology does not require the building occupy valuable natural land and fresh water resources, do not need to consume any additional chemical fuel, green and environmentally friendly, can effectively China has vast and abundant sunlight irradiation resources, and high energy consumption demand. Photovoltaic systems can be covered on the roofs of low-energy buildings or on the external walls of buildings to form a photovoltaic power generation system, and the installation process is relatively simple and easy to spread.

\section{Challenges and suggestions for the development of low-energy buildings}

\subsection{Lack of a sound industry management, norms and standards system}

The development of low-energy buildings in China is still immature, and the management system and standards of the industry are not perfect ${ }^{[11]}$. The on-site installation and management of low-energy buildings are far from standardized and refined, and there is a lack of strict industry construction guidelines, so the accuracy of installation is difficult to meet the high requirements of low-energy buildings. The quality inspection of prefabricated components has not yet formed a unified industry standard, resulting in the quality of some prefabricated components not meeting the requirements of low-energy buildings ${ }^{[12]}$. Therefore, it is necessary to speed up the establishment of a standardized and strict standard system for low-energy buildings according to the current actual situation in China.

\subsection{Inability to adapt to local conditions and lack of flexible application}

There are two major challenges in China, namely environment and climate, in developing low-energy buildings according to local conditions. First, the environment, China's vast land resources, unbalanced economic and social development, the climate of each region also exists a great difference, especially for some economically backward areas, the design of buildings need to fully integrate the actual characteristics of the local climate, but because the local economic and social development level is relatively backward, not able to provide more funds and advanced technology for low-energy building projects. The temperature difference between the four seasons is large, which brings a greater threat to the tasks and work of low-energy buildings. Secondly, the problem of climate, China's location across the latitude, resulting in different regions have obvious climate differences, different climate areas using a unified low-energy building does not play a good role in the energy-saving potential of low-energy buildings, only the development of low-energy buildings according to local conditions, in order to give full play to the maximum advantages of low-energy buildings ${ }^{[13]}$.

\subsection{Lack of evaluation of the whole life cycle of buildings}

The effect of energy saving and emission reduction in low-energy buildings should be based on the whole life cycle building saving and emission reduction data. Low-energy buildings should consume as little energy and money as possible and produce as little waste as possible from the development of original material production to building planning, design, construction, use, management and demolition. The whole life cycle of structural design should also consider the impact of post-earthquake restoration and other factors, improve 
the efficiency of material utilization, and focus on increasing the application of green building materials. At the production and construction stage, green construction is increased to save resources and protect the environment, thus reducing carbon emissions. At the present stage, the evaluation of the energy-saving effect of low-energy buildings is based on the evaluation of energy-saving during operation and use, which cannot reflect the energy consumption of buildings in a broad sense. A real low-energy building should reduce the consumption of resources and environmental pollution as much as possible during the whole life cycle of the building, rather than just relying on a lot of so-called energy-saving equipment to reduce energy consumption at a later stage, which is not the proper form of a low-energy building.

\section{Summary}

Low energy buildings are green, low-carbon, healthy and comfortable new high-quality buildings, which continuously improve the energy efficiency of buildings through envelope structures with higher thermal insulation and airtightness, the adoption of fresh air heat recovery technology, and the full use of renewable energy for heating and power generation. Although there are problems in the field of construction such as inadequate standard system, inflexible application and lack of evaluation of the whole life cycle of the building, its great advantages in terms of low carbon and comfort draw a beautiful blueprint for the realization of China's 2060 carbon neutral energy strategy, and low energy buildings have a very broad prospect and development space in the world and in China. By continuously making up for the shortcomings in the construction of low-energy buildings and thus giving full play to their greatest value, low-energy buildings will certainly help achieve carbon neutrality!

\section{Acknowledgments}

1. Project source: Ministry of Ecology and Environment. Project name: China's refrigeration maintenance industry good operation training consulting. (Project Number: C/III/S/19/031).

2. Project source: Science and Technology Research of the Education Department of Jilin Province. Project name: Application research of phase change heat storage floor in productive buildings. (Project Number: JJKH20211371KJ).

3. Project source: Natural Science Foundation of Jilin Province. Project name: Study on Two-dimensional Wave Resonance Mechanism and Energy Dissipation of Gas-solid Fluidized Bed (Project Number: YDZJ202101ZYTS180).

\section{References:}

1. Xi, J. (2020) Speech at the General Debate of the 75th Session of the United Nations General
Assembly. J. Bulletin of the State Council of the People's Republic of China, 28:5-7.

2. Roaf, S., Brotas, L., Nicol, F. (2015) Counting the costs of comfort. J.Building Research \& Information, 43 (3) :269-2733.

3. Gao, J. X., Li, G. Y., Zhang, Y,. Zou, C. X. (2021) "Analysis of ecological environmental protection goals, tasks and realization paths in the 14th Five-Year Plan. J. Environmental Protection, 49(02):45-51.

4. Zhang, S., Lv Yanjie, Xu Wei. (2020) Study on the best case control index and technical path for 64 ultra-low energy buildings. J. Building Science, 36(06):7-13+135.

5. Peng, M. Y. (2015) .Passive low energy building envelope key technology and material application. J. New Building Materials,42(01):77-82.

6. Pan, Z. Development of overall airtightness of buildings in China and suggestions[J]. Building energy efficiency,2018,46(11):86-89+109.

7. Xu, G. P. 2020. Research on the development countermeasures of clean energy heating and traditional energy heating. J. Green environmental protection building materials, (06):74-77.

8. Lu, C. p. (2019). Research on active-passive combination of solar energy + low valley electricity heating system. J. Heating and Cooling, (9):43-47.

9. Wei. Z., Wang, P. X. (2017) Reflection on the association between smart home and interior space design. J. Oriental collection, 01:26-27+57.

10. Tao, J., Wang, Y. Yang., Ren, N. N. (2017). Study on the demonstration project of ultra-low energy consumption building in Jilin Urban Construction College. J. Building Science, 33(06):8-14.

11. Chen, Q., Wang C. J., Li. J., Liu X.M. (2016). Research on key technologies of passive ultra-low energy buildings in cold regions. J. Journal of Shandong University of Construction, 31(01):19-26.

12. You, Y. N., Kang Y. T., Ma, J., Xing Y. R. (2019) Research and development of key technologies for passive ultra-low energy assembly buildings in China. J. Building Science, 35(08):137-142.

13. Xu, W., Yang X. Y., Zhang, S. (2018) Key problems and solution paths for the development of near-zero energy buildings in China. J. Building Science, 34(12):165-173. 